http://jmscr.igmpublication.org/home/ ISSN (e)-2347-176x ISSN (p) 2455-0450

crossref DOI: https://dx.doi.org/10.18535/jmscr/v9i4.18

Journal Of Medical Science And Clinical Research

\title{
Assessment of Knowledge, Attitude, and Practices about Blood Donation among First Year Students at a Govt Medical College in Uttar Pradesh
}

\author{
Authors \\ Imran A. Khan', Aditya Sharma', Dilkash Zaidi', Deepika Singh' \\ Vertika Singh ${ }^{1}$, Rahmat Ali ${ }^{2}$
}

${ }^{1}$ Second year Resident, Department of Community Medicine, BRD Medical College, Gorakhpur ${ }^{2}$ Professor and Head (Ortho department), Maharishi Vashishtha Autonomous State Medical College,

Basti, UP, India

\begin{abstract}
Background: Blood transfusion is among one of the essential strategies to manage patients suffering from various medical and surgical conditions. Blood for transfusion is obtained by replacement and voluntary donors. There is a great need to create awareness among the population at large and students about blood donation to maintain a regular blood supply. Medical and Paramedical students can be used as best model to lead this initiative.

Objectives: The shortage of blood in India is due to an increase in the demand, with less Practice of Voluntary blood donation and limited number of replacement blood donors. A study on the knowledge, attitude, and the practice may be proven useful in the successful implementation of the blood donation programme.

Materials and Methods: An institution based, cross-sectional survey using a pre-coded selfadministered questionnaire was conducted. A total of 135 medical students participated in the survey.

Results: Majority of respondents have adequate knowledge and good attitude; however, majority of them have poor practice. High number of participants agreed about encouraging public about voluntary blood donation. But not a single participant was able to respond to the knowledge part of the questionnaire with $100 \%$ accuracy. $19.3 \%$ participants don't know their own blood group.

Conclusion: Most of the students have good knowledge and attitude but poor practice towards blood donation. Information, Education and Communication (IEC) activities should be increased and regular seminars should be conducted to increase awareness among medical students for encouraging them to donate blood voluntarily and to motivate others to do so.
\end{abstract}

\section{Introduction}

Blood transfusion help in improving health and saving life of a patient, but many patients requiring transfusion do not have timely access to safe blood. Voluntary blood donation donations are still the only hope of life for the countless people that require blood transfusion every day.
The requirement of blood for the country is estimated to be 8.5 million to 10 million units/year, whereas the available supply is only 7.4 million units/year. ${ }^{1}$ India resembles many countries where blood services face the challenge of making sufficient blood available, demand exceeding supply and concerns regarding quality 
and safety. In India, before National AIDS Control Programme (NACP) was launched in 1992, the blood donation was mostly a family affair or a business. Traditionally the family members used to donate blood to each other or unknown donors used to earn money by donating blood. Ministry of health and family welfare, India 2017 guidelines for national blood transfusion services advises that donor motivation should be done by volunteers from the community using various communication methods to draw prospective donors to come to a blood bank or to a blood donation camp. ${ }^{2}$ When voluntary blood donation was propounded everywhere in the globe, it became famous in India also. Different studies suggest a wide gap between the supply and demand. To make the natter worse, there is a lack of awareness and motivation among the educated section of society that would have helped to resolve the crisis we face today. Youth are important segment of the population, and they are the hope of present and future source of safe blood supply. Thus, there is a need to explore the different aspects that may contribute toward voluntary blood donation. Knowledge, attitude, and practice (KAP) studies are a commonly used tool to investigate various aspects of human behavior. $^{3}$ A KAP survey is a representative study of a specific population to collect information on what is known, believed and done in relation to a particular issue.

Keeping above facts in the view and to fill the knowledge gap, the study aimed at determining awareness, level of knowledge, and attitudes towards voluntary blood donation among BRD Medical College students. Such information would definitely be helpful in planning for raising awareness and helping young people to donate blood in the country. Appropriate strategies could then be designed to improve blood donation practices of the medical students and general public.

\section{Aims and Objectives}

1. To assess the Knowledge, Attitude and Practice (KAP) of Blood Donation among MBBS first year students of BRD medical College.

2. Providing health education to MBBS students regarding voluntary blood donation.

\section{Materials and Methods}

A cross sectional observational study was conducted among first year undergraduate medical students of Baba Raghav Das Medical College Gorakhpur, Uttar Pradesh during NovemberDecember 2019. All the students of first semester were approached, sampling was not done.

A semi-structured questionnaire on Blood Donation was designed after reviewing the literature from similar studies in the department with consultation of senior faculty. The questionnaire was framed to collect information on demography, knowledge, attitude and practice towards blood donation. A pilot study was undertaken to validate study protocol with a sample of 30 individuals, to know the average time required for completing the questionnaire and to ensure that it is appropriate and understandable to students. Based on feedback obtained from pilot study the questionnaire was re-framed after making necessary amendments to make it simple and easy to understand. The questionnaires were distributed by the researchers to the students in lecture halls and took about 30 minutes to complete. To maintain confidentiality numbers were used in the questionnaires instead of respondents' names for the purpose of gathering information. Data were analyzed by using IBM SPSS software. A lecture regarding blood donation was arranged for the participants regarding blood donation to fill the knowledge gap after collecting filled questionnaire.

\section{Ethical Considerations}

We obtained approval by the institute ethical committee. The purpose of the study was 
explained to the students and informed consent obtained. Participation was entirely voluntary.

\section{Results}

A total of 135 Students participated in the study, of whom 77 (57\%) were male and 58(43\%) females. The age range was 17-27years, the mean age being 19.76 years (Table 1). Those students who had donated blood have more adequate knowledge about blood safety and donation as compared to those who have had never donated blood. This difference was statistically significant. Majority of the participants did not have a complete knowledge regarding the various aspects of voluntary blood donation. The most common reason for their satisfaction was helping others and saving someone's life.

Table: 1 Characteristics of participants

\begin{tabular}{|c|c|c|}
\hline Sociodemographic variable & Frequency & Percentage \\
\hline \multicolumn{3}{|l|}{ Gender } \\
\hline Male & 77 & 57 \\
\hline Female & 58 & 43 \\
\hline \multicolumn{3}{|l|}{ Marital status } \\
\hline Single & 129 & 95.6 \\
\hline Married & 6 & 4.6 \\
\hline \multicolumn{3}{|l|}{ Residence } \\
\hline Rural & 42 & 31.1 \\
\hline Urban & 93 & 68.9 \\
\hline \multicolumn{3}{|l|}{ Diet } \\
\hline Vegetarian & 49 & 36.3 \\
\hline Nonvegetarian & 86 & 63.7 \\
\hline \multicolumn{3}{|l|}{ Alcohol } \\
\hline Yes & 3 & 2.2 \\
\hline No & 132 & 97.8 \\
\hline \multicolumn{3}{|l|}{ Age (year) } \\
\hline $17-20$ & 100 & 74.1 \\
\hline $21-24$ & 30 & 22.3 \\
\hline $25-27$ & 5 & 3.6 \\
\hline
\end{tabular}

Table 2: Distribution of blood groups as reported by the Study participants

\begin{tabular}{|l|c|c|}
\hline Blood group & Frequency & Percentage \\
\hline A Negative & 1 & 0.7 \\
\hline A Positive & 19 & 14.1 \\
\hline B Negative & 1 & 0.7 \\
\hline B Positive & 43 & 31.9 \\
\hline AB Negative & 5 & 3.7 \\
\hline AB Positive & 12 & 8.9 \\
\hline O Negative & 0 & 0 \\
\hline O Positive & 28 & 20.7 \\
\hline Don't know & 26 & 19.3 \\
\hline
\end{tabular}

Knowledge of study participants regarding blood donation

Out of 135 participants $97.8 \%$ opine that their blood can save someone's life. One person's blood can benefit 4 persons by different components, this fact is known to only $17 \%$ students, $63.7 \%$ students were not sure about the answer, rest responded incorrectly. $61.5 \%$ 
participants knew correctly that blood donors also have some health benefits to donors. $63.7 \%$ participants know correctly that humane blood has no replacement (Table 3).19.3\% participants don't know their own blood group. (Table 2)

Table: 3 Knowledge of study participants about blood donation

\begin{tabular}{|l|c|c|}
\hline Knowledge & Correct & Percentage \\
\hline Age criteria & 29 & 21.5 \\
\hline Weight criteria & 17 & 12.6 \\
\hline Hemoglobin criteria & 44 & 32.6 \\
\hline Duration from last donation & 49 & 36.3 \\
\hline HIV status of donor & 132 & 97.8 \\
\hline HbsAg status of donor & 110 & 81.5 \\
\hline Menstruating women & 73 & 54.1 \\
\hline Pregnant women & 119 & 88.1 \\
\hline Lactating mother & 73 & 54.1 \\
\hline Malaria patient & 124 & 91.9 \\
\hline Dengue patient & 124 & 91.9 \\
\hline Controlled diabetes & 58 & 43.0 \\
\hline Controlled hypertension & 83 & 61.5 \\
\hline Blood can save someone's life & 132 & 97.8 \\
\hline One unit benefit 4 people & 23 & 17 \\
\hline Blood donation has health benefit & 83 & 61.5 \\
\hline Blood can't be substituted & 86 & 63.7 \\
\hline Amount of blood during donation & 12 & 8.9 \\
\hline Donor's blood tested before transfusion & 133 & 98.5 \\
\hline Normal individual has enough blood to donate & 121 & 89.6 \\
\hline Blood matching before transfusion & 123 & 91.1 \\
\hline
\end{tabular}

\section{Attitude of study participants regarding blood donation:}

Almost all students regard blood donation as a noble act of humanity (97\%) and most of the students $(94.8 \%)$ expressed their will to donate blood in future. There was a significant positive attitude towards blood donation as the majorities were willing to donate in the future for anyone and did not expect any post donation reward (Table 4). 53.3\% of our study subjects opine that voluntary blood donation is the best source of blood and blood products.

Table 4 Attitude of participants

\begin{tabular}{|c|c|c|}
\hline Positive Attitude & Frequency & Percentage \\
\hline Blood Donation is a noble work & 131 & 97.0 \\
\hline Would like to become a regular donor & 76 & 56.3 \\
\hline Will motivate others for blood donation & 123 & 91.1 \\
\hline Would like to donate blood in future when needed & 128 & 94.8 \\
\hline Will discuss about blood donation with friends and family & 129 & 95.6 \\
\hline
\end{tabular}

\section{Practice of Blood Donation}

Only $16(11.9 \%)$ participants donated blood till the commencement of the study, where $3.7 \%$ participants donated blood 3 or more times. This low percentage may be due to various factors as age of our participants, knowledge gap regarding benefits and safety of the procedure etc. Some important motivational factors for blood donation were Social media campaigns, thinking to help others in need and feeling of satisfaction after donation as told by donors.

\section{Discussion}

Human blood is essentially a vital, lifesaving component, capable of saving millions of lives if adequate availability is ensured in time. By virtue of their study and training, medical students have important roles in the blood transfusion services 
of the country. Youth including medical students who are generally healthy, enthusiastic and approachable easily as a group, if recruited early may become future donors and motivators. They are also a valuable and dependable source of information for public who come in contact with them every day, including family members and neighbors. Hence, it is essential to motivate and create awareness in them at an early stage itself. However, several studies involving medical students have expressed concern on lack of awareness and unsatisfactory voluntary blood donation practices among them. Probable factors may be misconceptions, perceived harms and risks, and lack of motivation among potential donors. Several studies have also reflected poor blood donation practice among the students in spite of relatively good knowledge and favorable attitude toward voluntary blood donation. The supply of safe blood can only be guaranteed with the help of regular, voluntary, non-remunerated blood donors. $^{4}$

The theme for Blood Donor Day 2020 was "Safe Blood Saves life" which was promoted with the slogan "Give blood and make the world a healthier place". It also stressed on the need for voluntary blood donation by healthy people. Replacement donors or family donors are people who donate blood to their family, friends, and relatives in time of need and account for approximately $45 \%$ blood donations in India. ${ }^{5}$ The WHO stresses the fact that replacement blood donation needs to be discouraged and replaced by voluntary, non remunerated blood donation. Paid/professional blood donation has been banned in India since January $1998 .^{6}$ Promotion of voluntary blood donation is done under safe blood program in India and 1st October is celebrated as National Voluntary Blood Donation Day. ${ }^{7}$ Voluntary unpaid blood donors who give blood purely for altruistic reasons has been reported with lowest prevalence of HIV, hepatitis viruses and other blood-borne infections whereas higher infection rates are found among family or family replacement donors who give blood only when it is required by a member of the patient's family or community. ${ }^{8}$ There are also some medical benefits of blood donation like the incidence of acute myocardial infarction is lesser in regular voluntary donors. ${ }^{9}$ Voluntary blood donation also increases the insulin sensitivity and thus helps in maintaining the equilibrium of glucose in the body. $^{10}$

Blood when needed can be replaced with blood or blood products only. There is only one amazing factory which makes the blood and that is the "Human body" and there is no substitute for it. Even after combined efforts of different Government and International Agencies such as Red Cross Society and World Health Organization, the supply of safe blood is still in short of global demand. ${ }^{12}$ It is generally recommended that the about $1-3 \%$ of the population should donate blood to meet a country's needs. ${ }^{13}$ WHO had adopted a policy at attainment of $100 \%$ voluntary non-remunerated blood donation by the year $2020 .{ }^{14}$ All countries in South East Asian Region are trying to eliminate culture of replacement donation and moving towards cent percent voluntary blood donation. ${ }^{15} \mathrm{~A}$ preliminary study in Nepalese college students revealed that medical students are better in knowledge as well as practice (Amatya et al., 2012). Blood donation camps, regularly organized within colleges and institutes, generate an encouraging environment for donation. As suggested by the responses that students also donate following other donors, a mix of past donors and new students could be helpful. Organizing such camps jointly by medical and other colleges could be very helpful to attract nonmedical students who have a lower rate of blood donation. Our findings are similar to that of Bharatwaj et al who found that all the participants in their study had a very incomplete knowledge regarding the various aspects of voluntary blood donation and that none of the participants were able to respond to the knowledge part of the questionnaire with $100 \%$ accuracy. ${ }^{16}$ It is surprising that $18.2 \%$ of the study subjects were 
not aware of their own blood group. This is quite higher compared to the study done by Sabu et al that found that $4.1 \%$ did not know their blood group. ${ }^{17}$ However, it is reassuring to know that the attitude towards blood donation was found largely positive with $97 \%$ considering blood donation to be an honorable act that is beneficial to society (Table 4). Similar results were obtained by Bharatwaj et al where $100 \%$ of the study subjects felt blood donation was a noble act. ${ }^{16}$

The non-donors with positive attitude and belief should be inspired and proper motivation lectures should be delivered about voluntary blood donation at regular interval. Moreover, opportunities should be provided to them to donate blood, whereas non-donors with the negative attitude should be educated about significance and health advantages of regular blood donation. Their misconception and apprehension about blood donation should be cleared and they should be inspired to become regular donors. Media can have a positive effect in encouraging blood donation. In a study conducted earlier, when adolescents were asked "what features should an advertising campaign for blood donors have?" Common responses were: simple, clear message that makes you think; photos of blood donors; a good-natured slogan; and, a famous person such as a footballer or singer who is a donor. ${ }^{18}$

Red Pulse Youth Trust is very active in Gorakhpur working for Poor, Needy and Emergency patients who need Blood. They are using social media in real time to connect between donors and needy for blood and blood products. This trust is also very much active in conducting Voluntary blood donation camps regularly. They are also using a vehicle with all advance medical facilities and Blood Donation Equipment which they use to promote and actual blood donation purpose in gatherings such as in market and other places. The vehicle serves the purpose of awareness, education, promotion and actual blood donation. Some noticeable reasons for not donating blood found in our study subjects were;
Did not get a chance, not aware regarding blood donation, Fear of needles, need to donate for friends/relatives in future, Parental restriction, Fear of being anemic and Fear of weight loss.

During the current pandemic of COVID-19 several patients have been treated by plasma donation which is an integral part of human blood. So, increasing awareness regarding this issue may protect more and more lives.

\section{Conclusion}

Availability of appropriate opportunities, better information, feeling of more social responsibility, and other motivational factors could play decisive roles in modulating students' behavior and practice. Further, efforts are necessary to motivate students towards regular VBD than donating at random and only when a need for blood transfusion presented.

It is important to create opportunities regarding blood donation, but it is equally important to spread the awareness of VBD. Information, Education and Communication (IEC) activities should be increased and regular seminars should be conducted to increase awareness among medical students for encouraging them to donate blood voluntarily and motivate others to do so. Famous personalities, religious leaders, regular peer donors and persons saved by blood donation should be approached to encourage students to donate blood during blood donation campaigns. Strategies should also be designed to encourage the students to donate blood voluntarily. For this it may be helpful to incorporate blood donation topic in to the existing curriculum and mass media, collaborative work with different national and international institution are important.

\section{Limitation of the Study}

Major limitations of our study were those inherent to most studies on knowledge, attitudes and practices. The responses might be influenced by socially desirable attributes and there is the possibility of both recall bias and interviewer bias. Secondly, since Gorakhpur is a multicultural city 
with a broad diversity and the students were from only one medical college and hence, it will not be appropriate to extrapolate the result which we have obtained, to the students of all medical college or general population. The present study may also have some validity issues and sample size.

\section{Acknowledgments}

We would like to express our appreciations to all students who participated in the study. We are grateful to professor D K Srivastava, professor and head community medicine, BRD Medical College for his guidance. We are also thankful to Dr Suresh Singh Associate Professor in the Department of Anesthesiology BRD Medical College Gorakhpur for his guidance and help in the present study. Last but not the least we are also thankful to Dr Hari Shankar Joshi Professor and head department of community medicine, AIIMS, Gorakhpur, for his help and Guidance in conducting the present study. The authors are also thankful to researchers, authors, publishers of all those articles, journals and books from where the literature for this article has been reviewed and discussed.

Conflicts of Interest: There are no conflicts of interest.

\section{References}

1. Umakanth Siromani, Thasian $\mathrm{T}$, Rita Isaac, Joy John Mammen; Where do we Stand Towards 100\% Voluntary Blood Donation - are we Really Moving Towards Achieving the Goal? International Journal of Emergency Mental Health and Human Resilience, Vol. 17, No.3, pp. 607-608, ISSN 1522-4821.

2. Guidelines for blood donor selection and blood donor referral. Ministry of health and family welfare, India. 2017.

3. Launiala A. How much can a KAP survey tell us about people's knowledge, attitudes and practices? Some observations from medical anthropology research on malaria in pregnancy in Malawi. Anthropol Matters J 2009; 11:1-13.

4. Blood Safety and Availability Fact Sheet No. 279. Reviewed June 2015.

5. Fordham J, Dhingra N. Towards $100 \%$ voluntary blood donation: A Global Framework for Action. Geneva: WHO; 2010.

6. Government of India. Voluntary Blood Donation Programme-An Operation Guideline: NACO. New Delhi: Ministry of Health and Family Welfare, Government of India; 2007

7. kishore J. National Health Programs of India. 9th ed. Delhi: Century publications; 2011.

8. Universal access to safe blood transfusion. WHO. Switzerland: 2012.

9. Zago A., Silveira M.F., Dumith C.S. Blood donation prevalence and associated factors in Pelotas, Southern Brazil. Rev Saudi Publica. 44(1):112-120, 2010.

10. Real JMF, Bermejo AL, Ricart W. Iron stores, blood donation and insulin sensitivity and secretion. Clin Chem 2005; 51:1201-5.

11. Kulkarni P, Kulkarni A. Mass counseling: Effective tool to improve knowledge, attitude and behaviour regarding blood donation. Ann Med Health Sci Res 2014; 4:90-4.

12. Damesyn MA, Glynn SA, Schreiber GB, Ownby HE, Bethel J, Fridey $J$, et al. Behavioral and infectious disease risks in young blood donors: Implications for recruitment. Transfusion. 2003; 43:1596603.

13. Fordham J, Dhingra N. Towards $100 \%$ voluntary blood donation: A Global Framework for Action. Geneva: WHO; 2010.

14. Blood Safety and Donation: Fact Sheet No. 279. June 2008, Available at: 
http://www.who.int/mediacentre/factsheets /fs $279 / \mathrm{en} /$.

15. Bharucha ZS. Donor management in South East Asian Region (SEAR). Dev Biol (Basel). 2005; 120:145-53.

16. Bharatwaj RS, Vijaya K, Rajaram P. A descriptive study of knowledge, attitude and practice with regard to voluntary blood donation among medical undergraduate students in Pondicherry, Indian Journal of Clinical and Diagnostic Research. 2012 May (Suppl-2), Vol-6(4): 602-604.

17. Sabu KM, Remya A, Binu VS, Vivek R. Knowledge, Attitude and Practice on Blood Donation among Health Science Students in a University campus, South India. Online $\mathbf{J}$ Health Allied Scs. 2011;10(2):6

18. Zito E, Alfieri S, Marconi M, Saturni V, Cremonesi G. Adolescents and blood donation: motivations, hurdles and possible recruitment strategies. Blood Transfus. 2012; 10: 45-58. 